\title{
Deactivation Mechanism of Titania Catalyst
}

\author{
Mansour A. Al-Shafei ${ }^{1}$, Ahmed K. Al-Asseel ${ }^{1}$, Abdulhadi M. Adab ${ }^{2}$, Hasan A. Al-Jama ${ }^{1}$, Amer A. Al-Tuwailib ${ }^{1}$ \\ \& Shouwen X. Shen ${ }^{1}$ \\ ${ }^{1}$ Research \& Development Center, Saudi Aramco, Dhahran, Saudi Arabia \\ ${ }^{2}$ Shedgum Gas Plant Department, Saudi Aramco, Shedgum, Saudi Arabia \\ Correspondence: Mansour Al-Shafei Research \& Development Center, Saudi Aramco, Dhahran, Saudi Arabia, \\ Tel: 966-876-4360. E-mail: mansour.shafei@aramco.com
}

Received: July 26, 2016

Accepted: August 8, 2016

Online Published: August 27, 2016

doi:10.5539/jmsr.v5n4p22

URL: http://dx.doi.org/10.5539/jmsr.v5n4p22

\begin{abstract}
Catalyst deactivation is a well-recognized phenomenon in the petroleum and chemical processing industries. Identifying the root causes of this phenomenon is an important factor for enhancing catalyst efficiency and preventing undesirable failures. In this study, state-of-the-art instruments were utilized to investigate the causes of catalyst deactivation that led to the replacement of the catalyst bed in one of the sulfur recovery units at a Saudi Aramco gas plant. Titania catalysts have been examined to determine the inherent deactivation mechanism and also to find out the possibilities of its curement. Understanding the root cause of the deactivation is mandatory for field engineers to minimize future catalyst deactivation. The collected analysis data revealed that the deactivation mechanism occurred for the Ti catalyst due to irreversible chemical phase transformation of the catalyst caused by a temperature runway in the catalytic converter.
\end{abstract}

Keywords: gas processing, catalyst deactivation, XRD, ESEM, TGA, Claus, titania

\section{Introduction}

Hydrogen sulfide is a naturally occurring component of crude oil and natural gas.

Petroleum oil and natural gas are the products of thermal conversion of decayed organic matter (kerogen) that is trapped in sedimentary rocks. High-sulfur kerogens release hydrogen sulfide during decomposition, and this $\mathrm{H}_{2} \mathrm{~S}$ stays trapped in the oil and gas deposits (1). Significant quantities of natural gas resources around the world known to contain $\mathrm{H}_{2} \mathrm{~S}$. These have been difficult to produce in the past because of the tendency of sour gas to cause factual damage to the health, processes and environment (1). In the processes, $\mathrm{H}_{2} \mathrm{~S}$ causes corrosion problems especially in pipelines. However, the advent of corrosion resistance materials and advanced manufacturing techniques make it possible to handle sour gas as a by-product to manufacture highly valuable products (2). Therefore, several processes are used to handle natural gas in order to remove hydrogen sulfide (2). In natural gas processing, Claus process is the most predominant desulfurization technique that convert hydrogen sulfide into elemental sulfur ( 3 , 4). Typically, the fundamental behind this process relies on two conversion stages which are thermal and catalytic stages (5).

A typical Claus unit consists of a thermal stage followed by two or three catalytic stages (three is more common). Before each catalytic stage, reheating process take place to maintain the reaction conditions (5). A typical process flow diagram for Claus unit is shown http://hengyeinc.com/claus-catalyst/The thermal stage consists of a Reaction Furnace (RF), Waste Heat Boiler (WHB), and a condenser. In this stage, $1 / 3$ of the $\mathrm{H}_{2} \mathrm{~S}$ feed is burned inside the $\mathrm{RF}$ to $\mathrm{SO}_{2}$ and elemental sulfur. The resulting Sulfur is condensed by the 1st condenser and collected in the sulfur pit. Some of the generated $\mathrm{SO}_{2}$ further reacts with the $\mathrm{H}_{2} \mathrm{~S}$ to produce elemental sulfur and $\mathrm{H}_{2} \mathrm{O}$ while the remaining $\mathrm{SO}_{2}$ and $\mathrm{H}_{2} \mathrm{~S}$ are processed to the catalytic converters. It is important to note that the heat generated in this stage is recovered in the WHB. The main chemical reactions are shown below:

(Thermal Stage)

$$
\begin{aligned}
& 3 \mathrm{H}_{2} \mathrm{~S}+3 / 2 \mathrm{O}_{2} \rightarrow \mathrm{SO}_{2}+2 \mathrm{H}_{2} \mathrm{~S}+\mathrm{H}_{2} \mathrm{O} \\
& 3 \mathrm{H}_{2} \mathrm{~S}+3 / 2 \mathrm{O}_{2} \rightarrow 3 / 2 \mathrm{~S}_{2}+3 \mathrm{H}_{2} \mathrm{O} \\
& 2 \mathrm{H}_{2} \mathrm{~S}+\mathrm{SO}_{2} \rightarrow 3 / 2 \mathrm{~S}_{2}+2 \mathrm{H}_{2} \mathrm{O}
\end{aligned}
$$


The generated $\mathrm{SO}_{2}$ in the Reaction Furnace then reacts over the catalyst bed in the catalytic converters with the remaining $\mathrm{H}_{2} \mathrm{~S}$ to form elemental sulfur, which is removed from the process gas in the condenser by cooling and condensation process. The catalyst in the catalytic reactors serves to boost the sulfur yield according to the following chemical reaction:

$2 \mathrm{H}_{2} \mathrm{~S}+\mathrm{SO}_{2} \rightarrow 3 / \mathrm{xS}_{\mathrm{x}}+2 \mathrm{H}_{2} \mathrm{O}$ (Catalytic Stage)

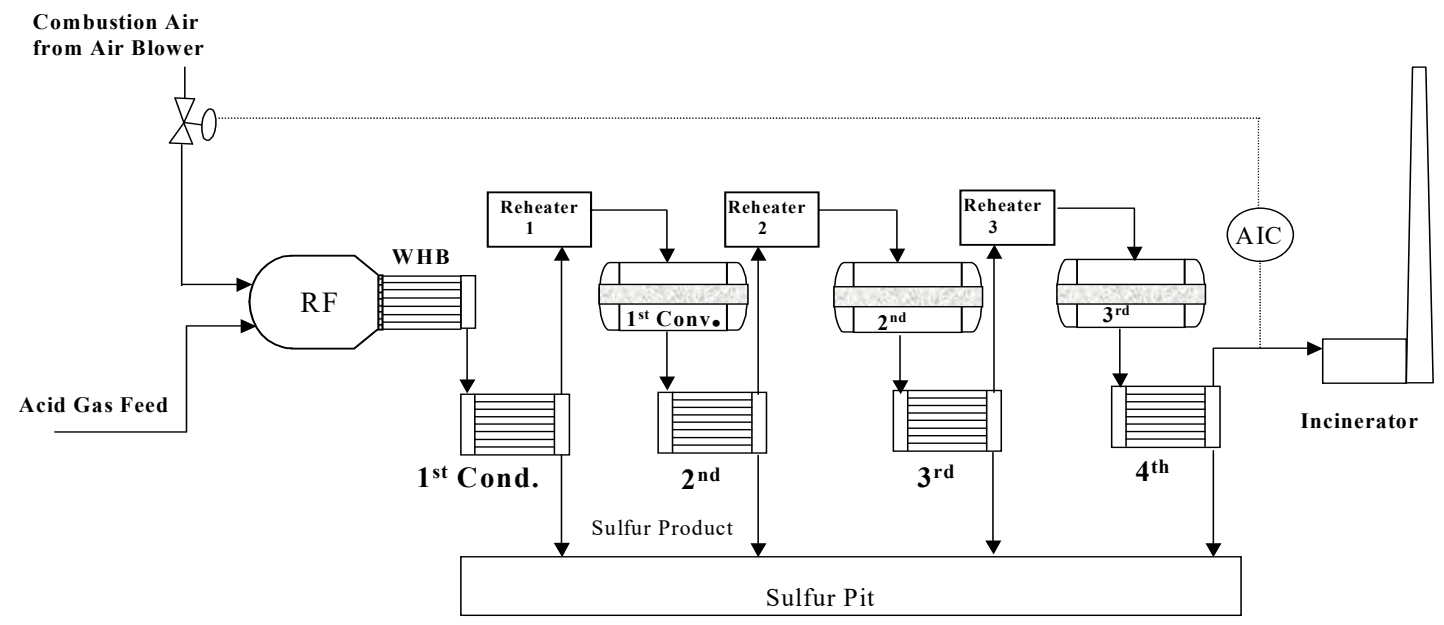

Figure 1. Claus Process Flow Diagram

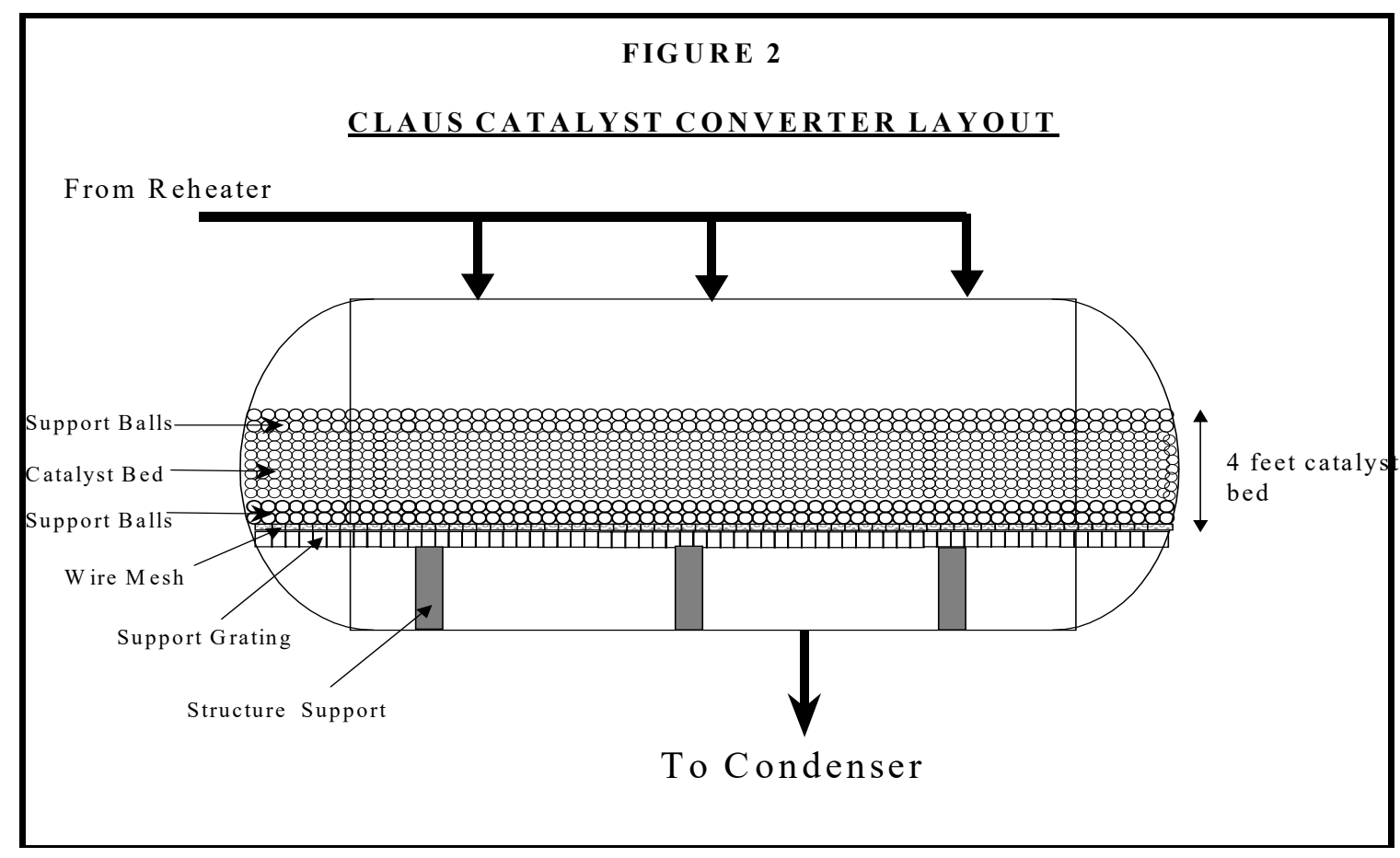

Figure 2. Claus Catalyst Converter Layout

The catalytic stage, which consists of a reheater, catalytic reactor, and condenser, is repeated two or three times to achieve the maximum overall sulfur recovery. Depending on the acid gas feed $\mathrm{H}_{2} \mathrm{~S} \%$ and the reaction furnace configuration, the sulfur conversion in the Reaction Furnace can reach up to $75 \%(6)$. The remaining is recovered in the subsequent catalytic stages (6). Figure 2 represents a typical layout of a catalyst converter. It consists mainly of 3-4 feet of rectangular activated alumina and titanium catalyst bed. The catalyst bed is typically covered by a 
3-6 inches layer of a bigger support alumina balls to hold the catalyst and also serves as gas distributor. Another support ceramic balls layer is used at the bottom of the catalyst bed to support the catalyst bed. This layer is placed on top of a wire mesh to prevent catalyst migration to condensers. The whole bed is supported by a support grating.

\subsection{Claus Catalyst}

Catalysts are the workhorses of chemical transformations in most industries. Approximately $85-90 \%$ of the products of chemical industry are made in catalytic processes (6). Claus process, where most of the applied catalysts are highly porous and with high surface areas such as aluminum oxide $\left(\mathrm{Al}_{2} \mathrm{O}_{3}\right)$, and titanium dioxide $\left(\mathrm{TiO}_{2}\right) .(7,8) \mathrm{It}$ is well known that catalysts differ from each other based on materials involved, prepration methods, and conditions (7). $\mathrm{TiO}_{2}$ based materials play a key role due to high stability in alkaline and acid media (7). Titanium dioxide (also known as Titina) is used as heterogeneous catalyst in many applications. For example, it is used as a photo-catalyst in solar cells for the production of hydrogen and electric energy. Alumina Catalyst is a hard working product that offers a high surface area for the conversion of $\mathrm{H}_{2} \mathrm{~S}$ and $\mathrm{O}_{2}$ to form elemental sulfur and water (7). The addition of a promoter to an activated alumina catalyst increases the hydrolysis of $\mathrm{CS}_{2}$ and $\mathrm{COS}$ into $\mathrm{H}_{2} \mathrm{~S}$, adds resistance to thermal aging, lower operating temperatures in the first Claus reactor, and an increase in working capacity during life span (7). Moreover, $\mathrm{TiO}_{2}$ is used in the Claus process to aid in the hydrolysis of carbonyl sulfide (COS) and carbon disulfide $\left(\mathrm{CS}_{2}\right)$ into hydrogen sulfide $\left(\mathrm{H}_{2} \mathrm{~S}\right)$, which can then be converted in elemental sulfur; this allows much higher quantities of sulfur to be recovered and lowers the quantity of COS and $\mathrm{CS}_{2}$ from going to flare (7).

$\mathrm{TiO}_{2}$ exists in three crystalline forms; anatase and rutile are the most common types, and the crystalline size of the rutile is always larger than the anatase phase (Bagheri, Muhd Julkapli, \& Bee Abd Hamid, 2014). Brookite is the third structure form, an orthorhombic structure, which is rarely utilized, and is of no interest for most applications (Bagheri, Muhd Julkapli, \& Bee Abd Hamid, 2014). Rutile phase is the most thermal stable among the three phases. Brookite and anatase crystalline, above $600 \mathrm{C}$, experience a phase transition and convert into the rutile phase (Bagheri, Muhd Julkapli, \& Bee Abd Hamid, 2014). The anatase phase contains zigzag chains of octahedral molecules linked to each other, while the rutile consists of linear chains of opposite edg-shared octahedral structure (Bagheri, Muhd Julkapli, \& Bee Abd Hamid, 2014). Generally, the anatase-to-rutile phase transformation occurs between $600-700^{\circ} \mathrm{C}$, but for certain applications, it is required that $\mathrm{TiO}_{2}$ anatase be stable at $900^{\circ} \mathrm{C}(\mathrm{Bagheri}$, Muhd Julkapli, \& Bee Abd Hamid, 2014). Generally, the anatase $\mathrm{TiO}_{2}$ nanoparticles are stabilized by the addition of cations (Bagheri, Muhd Julkapli, \& Bee Abd Hamid, 2014). The synthesis techniques of $\mathrm{TiO}_{2}$ usually require high temperatures to crystallize the amorphous material into one of the phases of $\mathrm{TiO}_{2}$, such Brookite, anatase, and rutile, consequently leading to large particles and typically nonporous materials (Bagheri, Muhd Julkapli, \& Bee Abd Hamid, 2014). Recently, low temperature synthesis methods resulted in crystalline $\mathrm{TiO}_{2}$ with a higher degree of control over the formed polymorph and its intra- or interparticle porosities (Bagheri, Muhd Julkapli, \& Bee Abd Hamid, 2014). There are reports on the formation of crystalline nanoscale $\mathrm{TiO}_{2}$ particle via solution based approach without thermal treatment with special focus on the resulting polymorphs, surface area, particle dimensions, and crystal morphology (Bagheri, Muhd Julkapli, \& Bee Abd Hamid, 2014). There are exceptional emphases on the sol-gel method via glycosylated precursor and also the miniemulsion method (Bagheri, Muhd Julkapli, \& Bee Abd Hamid, 2014). $\mathrm{TiO}_{2}$ possesses good mechanical resistance and stabilities in acidic and oxidative environments. In addition, $\mathrm{TiO}_{2}$ based catalyst has outstanding resistance towards corrosion in different electrolytic media and can be regarded as a support for heterogeneous catalysts which guarantees stability in electrochemical environment and commercial availability (Bagheri, Muhd Julkapli, \& Bee Abd Hamid, 2014). These properties make $\mathrm{TiO}_{2}$ a prime candidate for heterogeneous catalyst (Bagheri, Muhd Julkapli, \& Bee Abd Hamid, 2014).

There are only a few studies reporting a rutile catalyst support which resulted in higher catalytic activity compared to anatase, such as the oxidation of toluene, xylene, and benzene over rutile-supported $\mathrm{Cu}$ catalyst. In comparison, rutile is preferred as a model support for particles of metals in surface science studies (Bagheri, Muhd Julkapli, \& Bee Abd Hamid, 2014), due to its high crystal phase's thermodynamic stability. Furthermore, it is indicated that rutile and anatase differ noticeably in their ability of fixing particles of metals onto their respective surface (Bagheri, Muhd Julkapli, \& Bee Abd Hamid, 2014); whereas the strong metal support interaction is normally shown on anatase, this effect is not as significant on rutile. Inopportunely, the thermodynamic stability of $\mathrm{TiO}_{2}$ is comparatively low, and calcination would usually lead to the collapse of the porous structures (Bagheri, Muhd Julkapli, \& Bee Abd Hamid, 2014). Additionally, it is reported that calcination above $465^{\circ} \mathrm{C}$ has always resulted in the phase transition from anatase to rutile (Bagheri, Muhd Julkapli, \& Bee Abd Hamid, 2014). The phase transition could be connected to the growth of crystal size, which results in a severe reduction in specific surface 
area (Bagheri, Muhd Julkapli, \& Bee Abd Hamid, 2014). Consequently, this should also influence the overall catalytic performance of metal heterogeneous catalysts.

However, there are drawbacks in using $\mathrm{TiO}_{2}$ in Claus process which will be discuss in more details in this paper. Catalyst deactivation is very challenging task. In general, deactivation is inevitable, but it can be slowed or prevented and some of its consequences can be avoided. Several deactivation mechanisms have been identified and discussed extensively in the literature. These intrinsic mechanisms can be classified into the following distinct types which are poisoning, coking, sintering, solid-state transformation, and others. In general, they can be categorized as chemical, mechanical, or thermal mechanism (Coulsen \& Richardson, 1989). Understanding catalyst deactivation mechanisms is essential in order to better support field engineers to elongate the lifetime of processes catalysts.

\subsection{Deactivation Mechanisms}

Deactivation of catalysts is a problem that causes loss of catalytic rate with time. It classifies by type such as chemical, thermal, and mechanical. However, it is also classified by mechanisms such as poisoning, fouling, thermal degradation, vapor formation, vapor-solid and solid-solid reactions, and attrition/crushing. (10)

\subsubsection{Poisoning}

Poisoning is the loss of a catalyst activity due to the strong chemisorption on the active sites of impurities present in the feed stream. A poison may act simply by blocking an active site or may alter the adsorptivity of other species essentially by an electronic effect. Poisons can also modify the chemical nature of the active sites or result in the formation of new compounds so that the catalyst performance is altered (Gamson \& Elkins, 1953).

\subsubsection{Coking}

Coking for catalytic reactions involving hydrocarbons (or even carbon oxides) side reactions occur on the catalyst leading to the formation of carbonaceous residue (coke or carbon) which tend to physically cover the active surface. Coke deposits may deactivate the catalyst either by covering of the active sites, and by pore blocking. Mechanisms of carbon deposition and coke formation on catalysts have been detailed in literature (Gamson \& Elkins, 1953). The amounts of coke deposited into the catalyst pores may be estimated by burning the coke with air and recording the weight changes via TGA techniques and by monitoring the evolution of the combustion products $\mathrm{CO}_{2}$ and $\mathrm{H}_{2} \mathrm{O}$.

\subsubsection{Sintering}

Sintering refers to the loss of active surface due to structural modification of the catalyst. This is a thermal activated process. Sintering occurs both in supported metal and unsupported catalysts where the key variable is temperature, so operation at low temperatures greatly reduces the sintering rate (Gamson \& Elkins, 1953).

\subsubsection{Solid-State Transformation}

It is a process of deactivation that occurs at high temperatures and lead to the transformation of one crystalline phase into a different one. These processes may involve both metal-supported catalysts and metal oxide catalysts as well. For example, transformation of $\gamma$ - into $\delta-\mathrm{Al}_{2} \mathrm{O}_{3}$ with-wise decrease in the internal surface area from about $150 \mathrm{~m} 2 / \mathrm{g}$ to less than $50 \mathrm{~m} 2 / \mathrm{g}$ (Goar, 1968). Several of transformations are limited by the rate of nucleation. This process may occur due to the presence of foreign compounds in the lattice or on the surface. For example, $\mathrm{V}_{2} \mathrm{O}_{5}$ and $\mathrm{Fe}_{2} \mathrm{O}_{3}$ have been reported to favor the transformation of anatase-to-rutile (Gamson \& Elkins, 1953; Coulsen \& Richardson, 1989).

\subsubsection{Other Mechanisms of Deactivation}

Other deactivation mechanisms include masking or pore blockage, caused by physical deposit of substances on the outer surface of the catalyst which hinder the reactants from the active sites. In additional to the coke deposition, masking may occur during the processes where metals such as corrosion products deposit on the catalyst external surface (Gamson \& Elkins, 1953).

This paper presents a failure analysis that was conducted on Ti-based catalyst utilizing several analytical techniques to investigate the root causes resulted in the catalyst deactivation. This catalyst was deactivated in less than a year although the manufacturer specification stated that the lifetime of this catalyst is expected to last for five years. The preliminary investigation indicated that the deactivation was a result of temperature run-away in the catalytic converter. This study will investigate the changes occurred to the physical and chemical characteristic of titania catalyst that resulted in its deactivation. 


\section{Experimental Section}

In this study, fresh and plant spent catalyst samples were physically and chemically investigated using several analytical techniques. The spent Claus catalyst samples were collected from different rector layers:

\subsection{Surface Area and Pore Volume Analysis}

This analysis was performed to determine the surface areas before and after deactivation of the catalysts. The fresh and spent catalyst samples were ground to fine powder using a mortar and a pestle. The principle of the measurement is to use nitrogen molecule adsorption on the surface at 77 Kelvin to induce multi-layer physical adsorption. By measuring adsorbed amount of nitrogen at specific pressure of nitrogen, surface area and pore size distribution are estimated with B.E.T and B.J.H equations, respectively.

\subsection{Crush Strength Analysis}

This analysis was used to determine the strength of fresh and spent catalyst samples. It also determines the resistance of formed catalysts and catalyst carriers to compressive force. Such information will reflect the severity of the process to the catalyst.

\subsection{Total Carbon Analysis}

This analysis was carried out to determine carbon deposition in both the surface soot and the pore soot. 2-3 mg of the samples were weighted into disposable tin capsules and injected into a high temperature combustion reactor at $900^{\circ} \mathrm{C}$ in pure oxygen under static conditions. This method is intended to determine the amount of carbon deposited in/on catalysts using EA 1112 Elemental Analyzer.

\subsection{Total Sulfur Analysis}

This analysis was used to determine sulfur deposition in both the surface soot and the pore soot. The samples were analyzed using high-temperature tube furnace combustion method to determine the amount of sulfur deposited in/on the surface of the deactivated catalyst using ASTM D-4239-08 method.

\subsection{X-Ray Powder Diffraction and X-Ray Florescence Analysis}

$\mathrm{X}$-ray powder diffraction (XRD) was utilized to determine the catalyst crystalline inorganic phases/compounds for fresh and spent plant catalyst samples. In addition, XRD was also used to carry out an experiment known as Insitu XRD analysis for fresh catalyst sample. The experiment is designed to determine phase transformation during heating the sample from ambient temperature up to $1200^{\circ} \mathrm{C}$.

\subsection{X-Ray Florescence}

(XRF) was also used to determine the elemental chemical composition of the fresh and spent catalysts. For XRD analysis, the samples were ground to fine powder using a mortar and a pestle, and the fine powder was mounted in the XRD sample holder by back pressing.

The identification of the inorganic crystalline compounds present in the titania catalyst samples was achieved by using X-Pert High Score Plus program. The quantifications of the data were completed using either Rietveld refinement methods or RIR methods. For XRF, approximate $4 \mathrm{~g}$ of the powder was mixed and homogenized with $0.9 \mathrm{~g}$ of binder (Licowax C micropowder PM (Hoechstwax)). Then, the powder was pressed with 20 tons to pellet with $31 \mathrm{~mm}$ diameter prior to testing.

\subsection{Thermogravimetric Analysis (TGA)}

This technique was used to provide information on the chemical transformation of catalytic phases to non-catalytic phases. The samples were analyzed using TGA analyzer from ambient to $900^{\circ} \mathrm{C}$ at a rate of $10^{\circ} \mathrm{C}$ per minute under air. This was done to determine the material thermal stability and the loss on ignition (LOI) using SALAM 53006 method.

\subsection{Environmental Scanning Electron Microscopy (ESEM)/Energy Dispersive X-ray Analysis (EDS)}

ESEM was utilized to study topographic features of the catalyst samples to better understand the mechanisms of catalyst failures. A beam of electrons are focused on the catalyst surface to ionize the atoms of the catalyst in order to produce characteristic X-rays. These X-rays were processed to generate an EDS spectrum that represented the elemental composition and their intensity that are proportional to the concentration of the elements in the catalyst sample.

The electron beam penetrates 2-3 $\mu \mathrm{m}$ into the material so the composition is an average of the sample. The samples were analyzed using FEI Quanta 400 ESEM applying the procedures outlined in the Saudi Aramco Laboratory Analytical Method "SALAM" 024. The ESEM was operated at $15-30 \mathrm{kV}$, and $10 \mathrm{~mm}$ working distance. 
Backscattered electron images together with EDS X-ray spectra were acquired from different parts of the catalyst samples.

\section{Results and Discussion}

Deactivation is well-recognized phenomenon in the petroleum and chemical processing industries. Identifying the root causes of this phenomenon is an important factor to enhance catalyst efficiency and prevent undesirable failures.

The fresh and spent titanium dioxide $\mathrm{TiO}_{2}$ catalyst samples were physically and chemically characterized using different techniques such as surface area, pore volume, crush strength, thermal stability, chemical composition, and surface morphology. The collected data are presented in Table 1 . Since it is very important to determine the level of $\mathrm{CS}_{2}$ and $\mathrm{COS}$ in/on the surface of the catalyst. Because the activity of titania catalyst for pure Claus reaction at industrial operation conditions is so high and it always performs at equilibrium level, instead of the direct determination of the Claus activity the measurement of $\mathrm{CS}_{2}$ conversion over the catalyst becomes almost a unique and standard procedure (11). In addition, C-S compound, COS, is also formed in the same stage by a multitude of reactions. The presence of both $\mathrm{CS}_{2}$ and $\mathrm{COS}$ in the process gas flowing to the catalytic converters is very important as, if not destroyed in the $1^{\text {st }}$ converter, these substances place a limit on the total sulfur capture ability in the plant. (11). It is very important to determine the level of $\mathrm{CS}_{2}$ and $\operatorname{COS}$ in/on the surface of the catalyst.

Table 1 shows the properties of Ti fresh catalyst: The XRD data (Figures 4) showed the presence of anatase peaks which is the major phase of fresh titania catalyst with a minor phase of calcium sulphate. The patterns clearly exhibited strong diffraction peaks at 25 and 48 indicating $\mathrm{TiO}_{2}$ in the anatase phase. On the other hand, the XRD difractogram of the spent catalyst exhibited strong diffraction peaks at 27, 36 and 55 indicating $\mathrm{TiO}_{2}$ in the rutile phase with a minor phase of perovskite that was detected at 34 and 48 peak position (Figure 5). Nevertheless, titania normally undergoes anatase-rutile phase transformation in the temperature range $600-700^{\circ} \mathrm{C}$ (Gamson \& Elkins, 1953; Goar, 1968; Clark, Dowling, \& Huan, n.d.). For high temperature conversion of titania, a stable anatase phase is necessary. Both anatase and rutile are tetragonal in structure. Both structures are consisted of $\mathrm{TiO}_{6}$ octahedral, sharing four edges in anatase and two in rutile as illustrated in Figure 3. The anatase to rutile transformation is reconstructive transformation, which means that the transformation involves the breaking and forming of bonds (Goar, 1968). This is in contrast to a displacing transformation, in which the original bonds are distorted but retained. According to the XRD data the crystallite sizes are $11.5 \mathrm{~nm}$ and $408.9 \mathrm{~nm}$ of anatase in the fresh and rutile in the spent catalyst samples respectively. Changes in the titania phase is proportional to the significant changes in the surface area. The total surface area lost is about $98 \%$ which attributed to the formation of rutile phase (Table 1). These changes in the arrangements of $\mathrm{TiO}_{6}$ have effects chemical properties of titania catalysts.

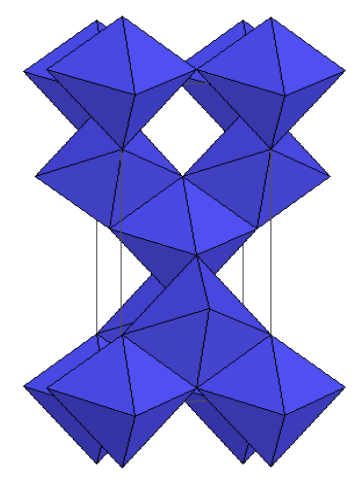

(A)

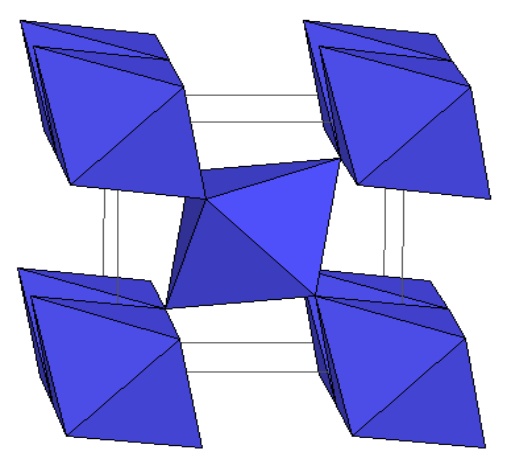

(B)

Figure 3. Three-dimensional representation of the (A) rutile and (B) anatase 


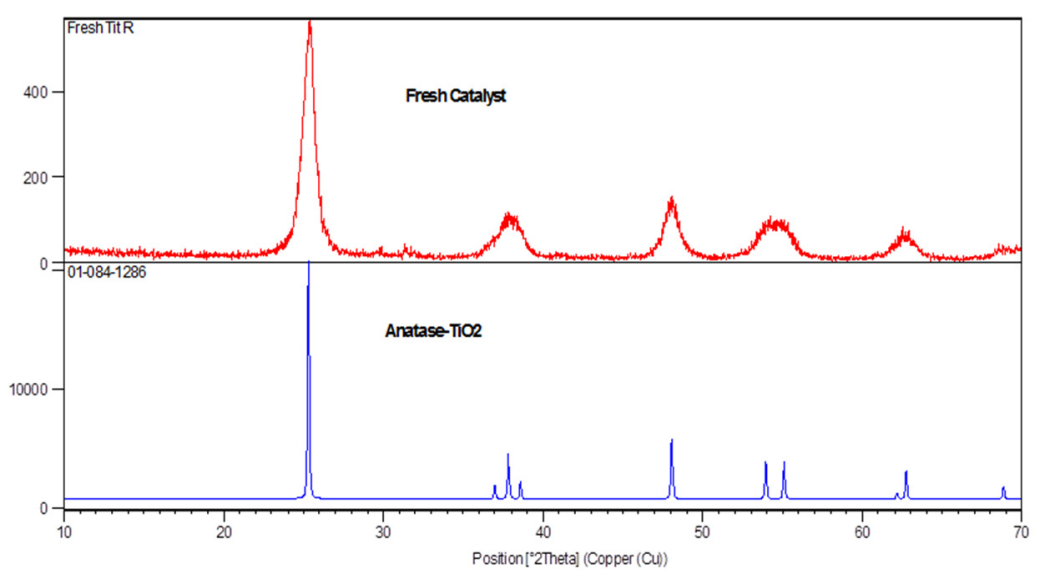

Figure 4. XRD Pattern of the fresh Ti Catalyst Sample

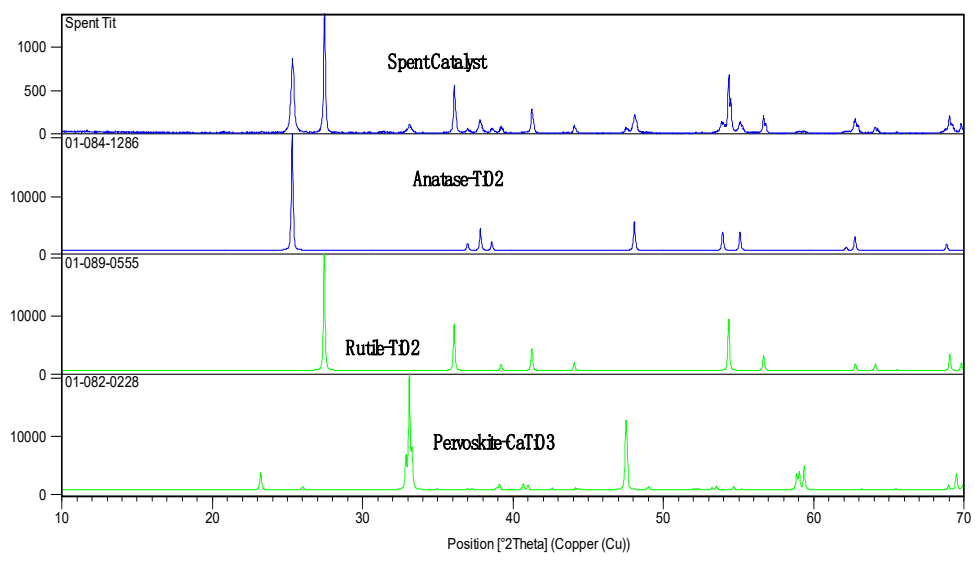

Figure 5. XRD Pattern of the spent Ti catalyst Sample

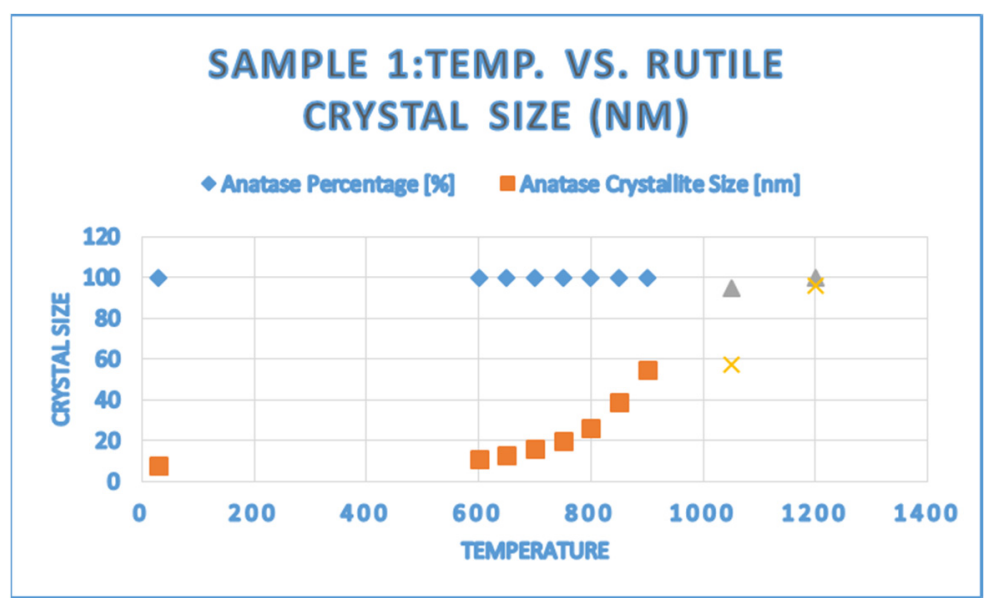

Figure 6. Temperature vs. anatase crystal size (nm) formation

Another significant change was observed in the pore volume analysis. It revealed substantial decrease in the porosity for the deactivated titania catalyst compared to the fresh catalyst samples. The change in the pore volume of the deactivated titania catalyst can be correlated with the increased crystallite size which lowered the porosity due to phase transformation as demonstrated by the X-ray diffraction patterns. Furthermore, a change was also 
observed in the crush strength where the fresh Ti catalyst showed superior mechanical strength compared to spent Ti catalyst (Crush strength $35.5 \mathrm{~N}$ for fresh Ti catalyst vs. 11.7 for spent Ti catalyst).

In literature, morphology of the catalyst plays a major role that influences its activity and selectivity (10). With the aid of ESEM images, it is possible to visualize the effects caused by temperature runway in the catalytic converter by comparing the micro-images of fresh and spent catalyst samples. The deactivation changed the morphological properties of the fresh catalyst. Fresh and deactivated catalyst samples were analyzed by SEM and ESEM. In this study it was found that the catalyst deactivation is not directly dependent on $\mathrm{CS}_{2}$ and COS content but it is highly influence by the catalyst shapes and pores structure. However, hydrocarbons deposition were detected on the surface of the deactivated catalyst surfaces such deposition contributes to decrease the catalyst porosity and ultimately affect the performance of the catalyst activity. Figure 6 shows homogenous structure with well-defined open pore with an average dimension of 10-100 nm. Such structure maximizes the contact between the reactants and the active parts of the catalyst and hence increases the activity. Maintaining these structural properties will certainly maximize the life time of the catalyst. In comparison, Figure 7 shows non-homogeneous structure with much closed pores. The micrographs also show collapsed pores full of hydrocarbons. It seems that runway temperature caused damaged to all types of pores which illustrates the mechanisms of deactivation. Nevertheless, the images in Figure 7 (C, D, and E) show that the catalyst cannot be regenerated or rejuvenated due to sever collapse of the catalyst pores. The EDS analysis data shows hydrocarbons laying down on the surface of the deactivated catalyst as shown in Figure 7 (E, F). However, it was difficult to look inside the pores since the SEM images shows that all the catalyst pores are fully damaged due to overheating temperature that caused to deactivation.

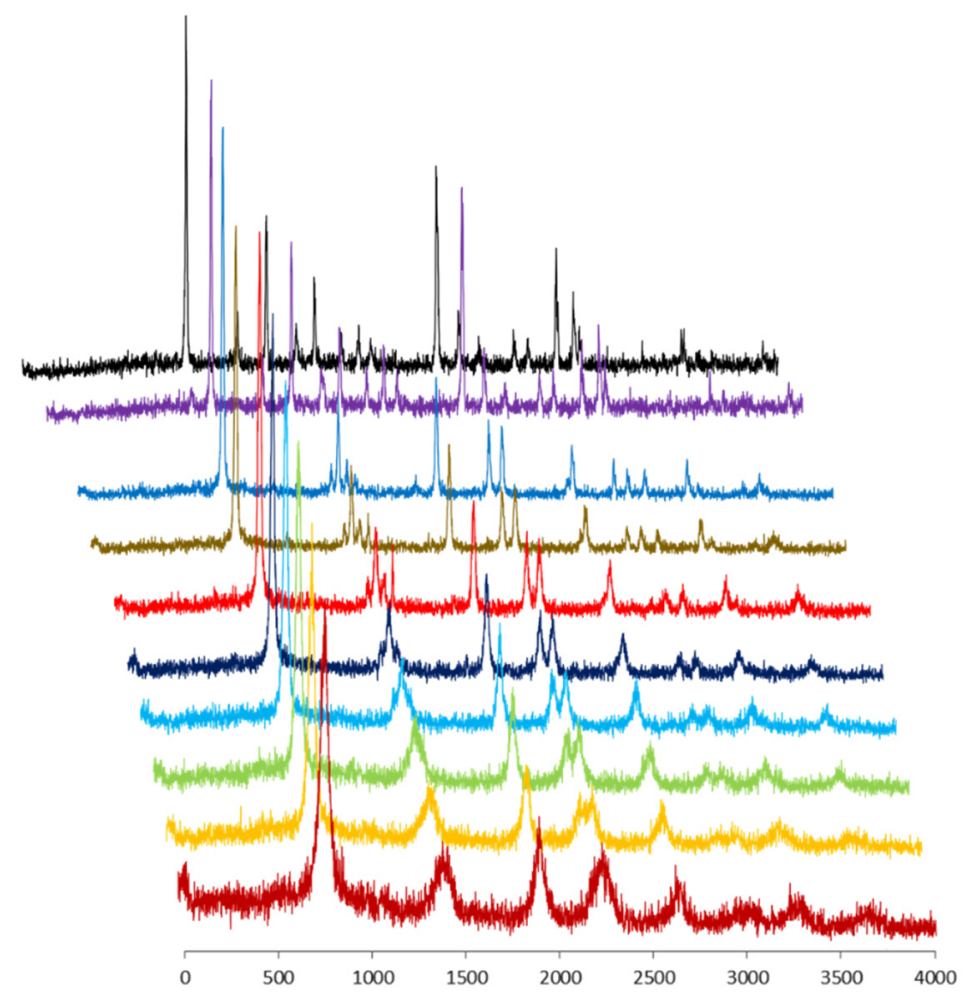

Figure 7. In-situ XRD Pattern: In-house calcination experiment of anatase from ambient to $1200^{\circ} \mathrm{C}$

In theory, catalyst mechanical properties are highly effected by structure of the catalyst. Due to deactivation, the spent Ti catalyst lost $67 \%$ of its strength (Table 1). In Addition, the lack of strength generates large amounts of dust which blocks catalyst pores which results in loss of catalytic active sites.

The TGA analysis in Figure 8 shows the difference between fresh and spent Ti catalyst samples. The spent Ti catalyst shows straight line from ambient temperature up to $900^{\circ} \mathrm{C}$ which illustrates that all the catalyst components had been decomposed. Where the fresh catalyst lost 2.5 (\% weight) at $130^{\circ} \mathrm{C}, 4.3(\%$ weight $)$ at $600^{\circ} \mathrm{C}$, and 6.2 (\%weight) at $900^{\circ} \mathrm{C}$. 
All results are in line with the phase transformation which is in this case cannot be regenerated or rejuvenated to the original phase due to breaking and formation of new bonds.

According to literature, anasate has a certain structure that effectively increases the sulfur conversion by reacting the generated $\mathrm{SO}_{2}$ with $\mathrm{H}_{2} \mathrm{~S}$ to produce elemental sulfur in the Claus process (6). Moreover, the catalyst performance is significantly affected by lay down of hydrocarbons that blocked the active sites and also phase transformation that caused breaking and formation of new bonds.

In order to better understand the Ti catalyst deactivation mechanism, in-house calcination experiments were carried out in 7 fresh catalyst samples calcined for 2 hours from room temperature up to $500^{\circ} \mathrm{C}, 600^{\circ} \mathrm{C}, 700^{\circ} \mathrm{C}, 800^{\circ} \mathrm{C}$, $900^{\circ} \mathrm{C}, 1000^{\circ} \mathrm{C}$, and $1200^{\circ} \mathrm{C}$. The resulted catalyst samples were analyzed using XRD, and ESEM techniques.

The XRD phase identification and quantification data (Table 2) shows that anatase $\mathrm{TiO}_{2}$ phase started to transform to rutile $\mathrm{TiO}_{2}$ phase at $800^{\circ} \mathrm{C}$. It shows that only $3 \mathrm{wt} . \%$ of anatase was converted to rutile phase, where $10 \mathrm{wt} . \%$ of anatase phase remained at $900^{\circ} \mathrm{C}$. This clearly shows that the temperature during the failure was beyond $900^{\circ} \mathrm{C}$, because the spent Ti catalyst contains only rutile phase as shown in Figure 5.

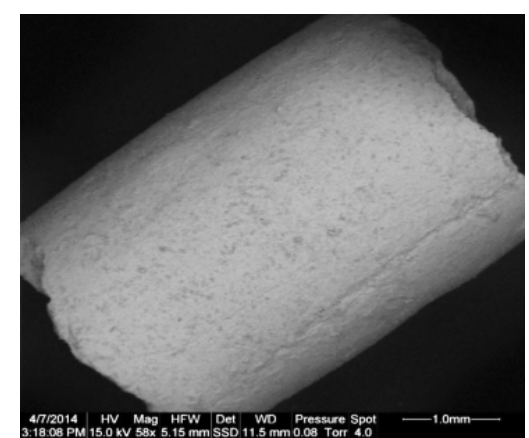

(A)

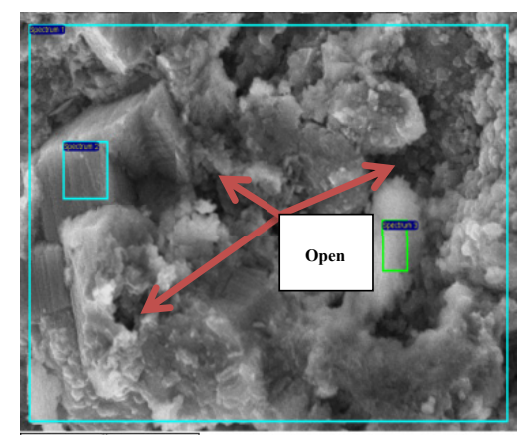

(C)

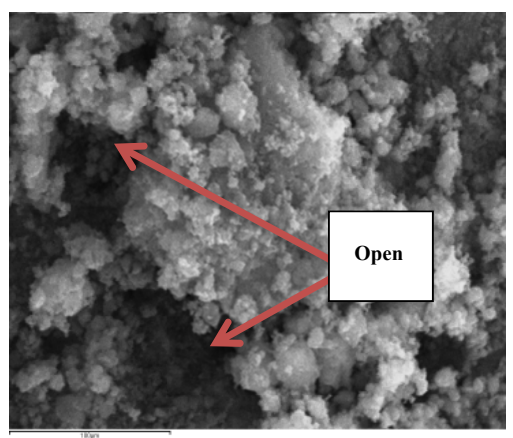

(B)

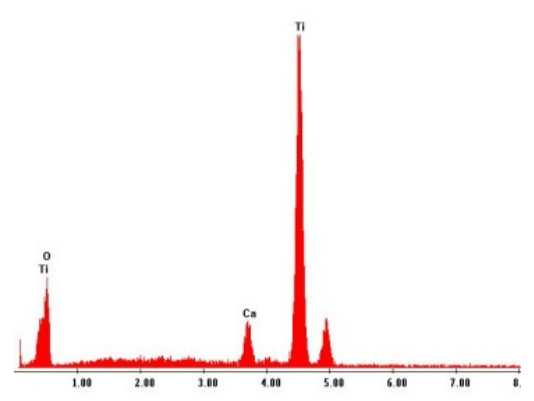

(D)

Figure 8. SEM images and EDS analylsis of fresh Ti catalyst: (A) Low SEM magnification of fresh Ti catalyst sample as received, (B) and (C) SEM images at 5000x of fresh Ti Catalyst showing open pores. And (D) EDS spectrum of fresh $\mathrm{Ti}$ catalyst that shows $\mathrm{Ti}, \mathrm{O}$ and $\mathrm{Ca}$ are the preeminent elements in the catalyst sample 


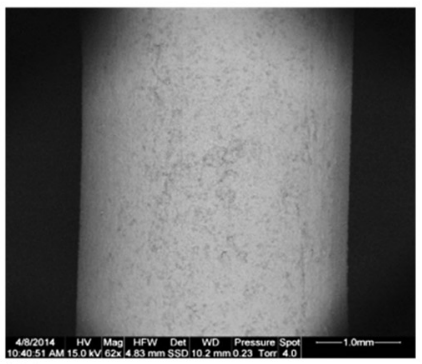

(A)

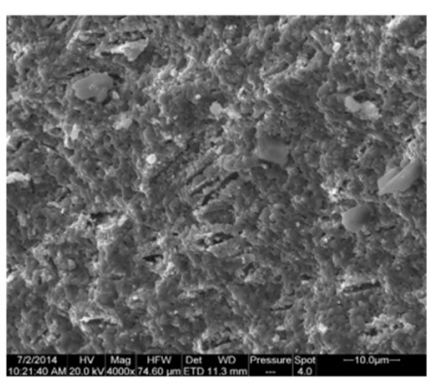

(C)

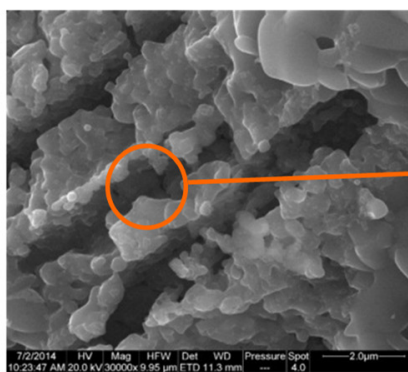

(E)

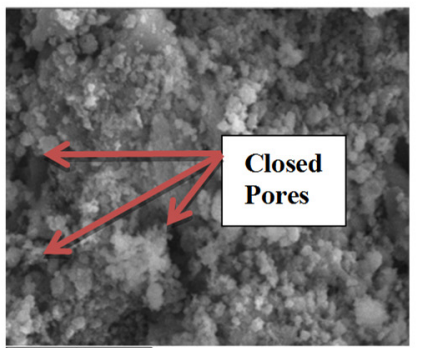

(B)

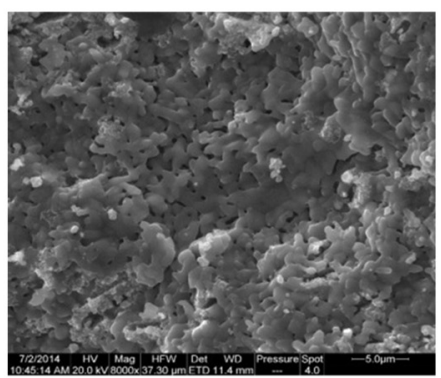

(D)

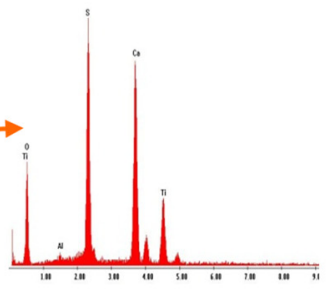

(F)

Figure 9: SEM images and EDS analysis of spent Ti catalyst: (A) Low SEM magnification of spent Ti catalyst sample as received. (B) SEM image of spent catalyst showing closed pores due to deactivation process. (C) (D) SEM images of damaged pores caused by temperature runway in the catalytic converter. (E) (F) SEM image of damaged Ti catalyst surface showing deposition of sulfur content (EDS) caused by deactivation

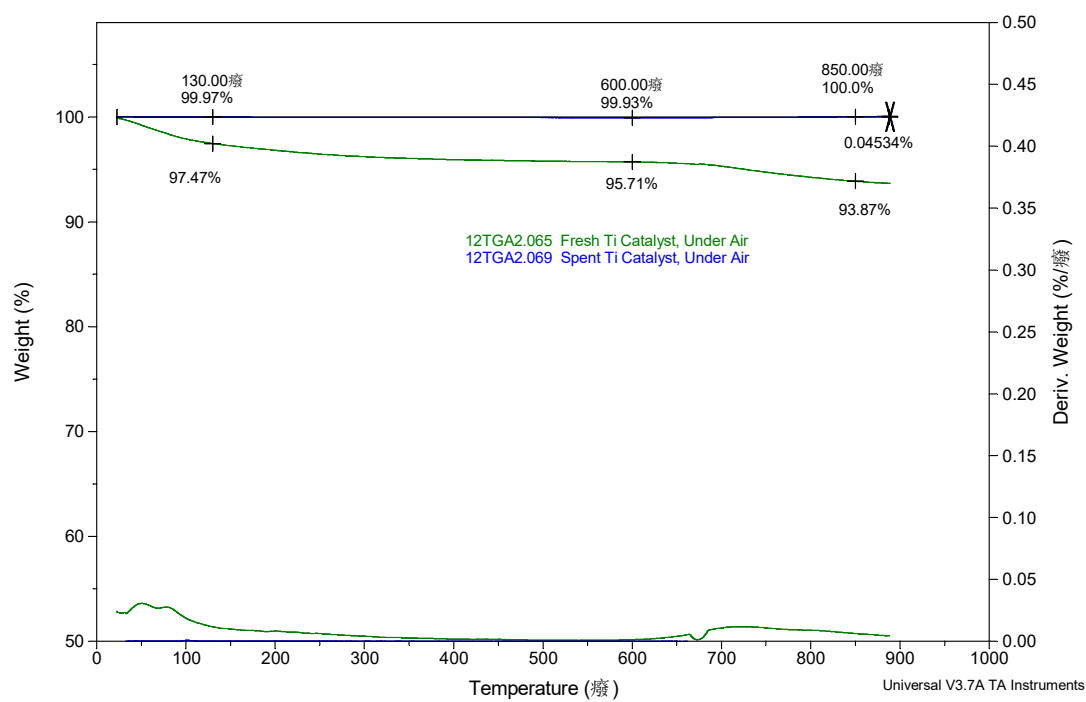

Figure 10. TGA analysis of fresh and spent Ti catalyst 
Table 1. Physical properties and XRD composition of the fresh and spent Titania catalyst

\begin{tabular}{lccc}
\hline Property & Fresh Ti Catalyst & Spent Ti Catalyst & Remark \\
\hline Surface Area, $\mathrm{m}^{2} / \mathrm{g}$ & 134.2 & 2.1 & Lost 98\% of surface area \\
Pore Volume, cc/g & 0.27 & $0.47 \times 10^{-2}$ & Lost 98\% of pore volume \\
Crush Strength, N (Ibs) & 35.5 & 11.7 & Lost 67\% of strength \\
Major Crystalline Phase (XRD) & ${\text { Anatase- } \mathrm{TiO}_{2}}^{2}$ & Rutile- $\mathrm{TiO}_{2}$, & Inactive catalyst \\
Minor Crystalline Phase (XRD) & $\mathrm{CaSO}_{4}$ & Perovskite-CaTiO & Reactions due to temperature runaway \\
Colour & White & Grey & Change in color \\
\hline
\end{tabular}

Table 2. XRD Phase Identification and Quantification (in wt.\%) of Catalyst Samples

\begin{tabular}{llllll}
\hline \multirow{2}{*}{ Compounds } & \multicolumn{5}{c}{ Catalyst Treated Temperature } \\
\cline { 2 - 6 } & $500{ }^{\circ} \mathrm{C}$ & $600{ }^{\circ} \mathrm{C}$ & $700{ }^{\circ} \mathrm{C}$ & $800{ }^{\circ} \mathrm{C}$ & $900{ }^{\circ} \mathrm{C}$ \\
\hline Anatase- $\mathrm{TiO}_{2}$ & $100 \%$ & $100 \%$ & $100 \%$ & $97 \%$ & $16 \%$ \\
${\text { Rutile- } \mathrm{TiO}_{2}}$ & - & - & - & $3 \%$ & $84 \%$ \\
\hline
\end{tabular}

\section{Conclusion}

- Different structures lead to different physical properties.

- Hydrocarbon compounds were detected on the surface of the deactivated catalyst.

- Loss of catalyst activity was due to chemical conversion of anatase to rutile caused by temperature runaway inside the Catalytic Converter.

- Increasing the temperature caused significant changes in the textural properties of fresh catalyst.

- Changes in the titania phase was paralleled by significant changes in the surface area at temperature above $650^{\circ} \mathrm{C}$. The spent catalyst lost $98 \%$ of the total surface area which attributed to the formation of rutile phase.

- The Nitrogen adsorption analysis showed that the deactivated titania catalyst suffered significant loss of micro-pores.

- The chemical characterization data showed that the deactivation was not due to surface contamination. However, the detected hydrocarbons on the surface of the deactivated catalyst samples was due inability of the catalyst to covert the reactants to products.

- The presented ESEM images illustrated a wide application of this method in the field of heterogeneous catalysis. ESEM investigations combined with spectroscopic diffraction and other spectroscopic methods were very successful in understanding the cause of catalyst deactivation.

- It is found that the anatase to rutile phase transformation was accelerated by increasing temperature.

\section{Acknowledgment}

Authors would like to thank Sayed R. Zaidi, and Akram A. Alfliow for their involvements in the research project. Ki-Hyouk X. Choi, and Abed T. Al-Harthi for their contributions to this study.

\section{References}

Al-Haji, M. N., \& A-Adab, A. M. (2001). Claus Catalyst Sulfur Wash: A Successful Technique to Restore Normal Pressure Drop. Oil \& Gas Journal, 99(24).

Al-Shafei, M. (n.d.). Internal technical report.

Argyle, M. D., \& Bartholomew, C. H. (2015). Heterogeneous catalyst deactivation and regeneration: A review. Catalysts, 5(1), 145-269.

Arrouvel, C., Digne, M., Breysse, M., Toulhoat, H., \& Raybaud, P. (2004). Effects of morphology on surface hydroxyl concentration: a DFT comparison of anatase-TiO 2 and $\gamma$-alumina catalytic supports. Journal of Catalysis, 222(1), 152-166.

Bagheri, S., Muhd Julkapli, N., \& Bee Abd Hamid, S. (2014). Titanium dioxide as a catalyst support in heterogeneous catalysis. The Scientific World Journal, 2014.

Bartholomew, C. H. (2001). Mechanisms of catalyst deactivation. Applied Catalysis A: General, 212(1), 17-60. 
Batzill, M., Morales, E. H., \& Diebold, U. (2006). Influence of nitrogen doping on the defect formation and surface properties of TiO 2 rutile and anatase. Physical review letters, 96(2), 026103.

Beauchamp, R. O., Bus, J. S., Popp, J. A., Boreiko, C. J., Andjelkovich, D. A., \& Leber, P. (1984). A critical review of the literature on hydrogen sulfide toxicity. CRC Critical Reviews in Toxicology, 13(1), 25-97.

Clark, P. D., Dowling, N. I., \& Huan, M. (n.d.). Fundamental and Practical Aspects of the Claus Sulfur Recovery Process, Alberta Sulfur Research Ltd., Calgary, Alberta, CanadaP.D. Clark, N.I. Dowling and M. Huan., Fundamental and Practical Aspects of the Claus Sulfur Recovery Process, Alberta Sulfur Research Ltd., Calgary, Alberta, Canada.

Clark, P. D., Dowling, N. I., \& Huang, M. (2008). Reversible deactivation of TiO 2 in CS 2 conversion associated with Claus reaction. Applied Catalysis A: General, 343(1), 104-108.

Clark, P. D., Dowling, N. I., \& Huang, M. (2008). Reversible deactivation of TiO 2 in CS 2 conversion associated with Claus reaction. Applied Catalysis A: General, 343(1), 104-108.

Claus Catalyst. (n.d.). In Hengye. Retrieved from http://hengyeinc.com/claus-catalyst

Coulsen, J. M., Richardson, J. F. (1989). Chemical Engineering (Vol 2, 3rd Ed.). Pergamon Press.

Farrauto, R. J., Dorazio, L., \& Bartholomew, C. H. (2016). Introduction to Catalysis and Industrial Catalytic Processes. Retrieved from http://www.wileyvch.de/books/sample/3527316728_c01.pdf

Forzatti, P., \& Lietti, L. (1999). Catalysis Today 52 (1999). 165 \pm 181.

Gamson, B. W., \& Elkins, R. H. (1953). Sulfur from Hydrogen Sulfide. Chemical Engineering Progress, 49(4), 203-215.

Goar, B. G. (1968). Today's Sulfur Recovery Processes. Hydrocarbon Processing, 248-252.

Larraz, R. (1999). Hydrocarbon Processing.

Mohammad, N. A. H., \& Abdulhadi, M. A. A. (2001). Catalyst Sulfur Wash. 51st Annual Laurance Reid Gas Conditioning Conference, Norman, Oklahoma, February 25 - 28, 2001.

Shafei, M. A., \& Dutta, T. K. (2000). Proceding of the world petroleum Congress. Calgary, Canada, 2000

\section{Copyrights}

Copyright for this article is retained by the author(s), with first publication rights granted to the journal.

This is an open-access article distributed under the terms and conditions of the Creative Commons Attribution license (http://creativecommons.org/licenses/by/4.0/). 